\title{
Patients' Lived Experiences of the Care Provided Before and After Caesarean Sections in the City of Tshwane, Gauteng, South Africa
}

\author{
Takalani A. Mudau \\ https://orcid.org/0000-0001-6150-3128 \\ Tshwane University of Technology, \\ South Africa \\ asmeraldamudau@gmail.com
}

Tshidi M. E. Masala-Chokwe

https://orcid.org/0000-0001-8271-1890

Tshwane University of Technology,

South Africa

chokweme@tut.ac.za

\author{
Tendani S. Ramukumba \\ https://orcid.org/0000-0003-4625-1676 \\ Tshwane University of Technology, \\ South Africa \\ ramukumbats@tut.ac.za
}

\section{Abstract}

A caesarean section is an incision of the abdomen and uterine walls to deliver the foetus. An emergency caesarean section may be performed if complications during pregnancy or labour arise. Various indications such as abnormal presentation, a previous caesarean section, and other related conditions may need an elective caesarean section. In South Africa, the national average caesarean section rate between 2015 and 2016 was 26.2 per cent, whereas the rate in district hospitals was 24.1 per cent. At a community hospital in the City of Tshwane, the caesarean section rate of 32 per cent in 2015 was recorded as high. The aim of this research was to explore and to describe patients' lived experiences of the care provided before and after a caesarean section in the City of Tshwane, Gauteng, South Africa. To achieve the aim of the study, a qualitative, exploratory, descriptive study was conducted. The sampling method used was purposive, and the sample size was determined by data saturation. An interview schedule was used to collect the data. The study concluded that some women were satisfied with the care provided, whereas the majority were dissatisfied. The need for strategies to improve such care provided by nurses and midwives was highlighted. Multidisciplinary teams have to acknowledge gaps and develop effective strategies to motivate nurses and midwives in the workplace to provide quality care. Research should be conducted to design an effective nursing framework for caesarean section care.

Keywords: nursing care, caesarean section, lived experiences, midwives, nurses

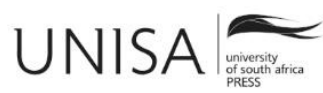

Journal title African Journal of Nursing and Midwifery https://upjournals.co.za/index.php/AJNM/index

https://doi.org/10.25159/2520-5293/8177 Volume 23 | No.2 | $2021 \mid$ |\#8177| 15 pages

ISSN 2520-5293 (Online), ISSN 1682-5055 (Print)

(C) The Author(s) 2021 


\section{Introduction and Background}

The World Health Organization (WHO 2015) states that caesarean section rates should not exceed 10 per cent to 15 per cent of the entire population in a country. According to Koffi et al. $(2017,1137)$, the caesarean section rates at hospitals in Cairo, Egypt, were between 35.2 per cent and 52.1 per cent in 2014. The caesarean section rate in Tanzania increased from 19 per cent to 49 per cent in the decade leading up to 2013. In addition, Koffi et al. $(2017,1134)$ found that emergency caesarean section rates had increased to 69.9 per cent in the total study population of hospitals situated in the Ivory Coast. Hoxha et al. $(2017,1)$ argue that caesarean sections are performed more often in private hospitals for profit, as compared to those in public non-profit hospitals. The researchers observed that despite the increasing number of caesarean sections, the quality of care provided to these patients before and after caesarean section needs improvement.

The WHO (2016) defines quality of care as the provision of healthcare services that improve and meet the desired outcomes of healthcare users. The quality of care can be enhanced by providing fair, patient-centred care, reducing harm, avoiding preventable injuries, providing evidence-based care, and delivering healthcare services in a costeffective manner. It is vital for doctors and midwives to explain the indications for a caesarean section to patients in plain language. Should the mother request a normal vaginal delivery after a previous caesarean delivery, she must be given the opportunity. However, the mother should be informed about the risks involved (Koffi et al. 2017, 1134). According to the Guidelines for Maternity Care in South Africa $(2015,56)$, a caesarean section may cause various complications such as sepsis, haemorrhage, injury to the bladder, and the formation of emboli. Moreover, future pregnancy may place the mother at risk for placenta praevia, placenta accreta, hysterectomy, ectopic pregnancy, and miscarriage. The National Department of Health $(2014,10)$ has developed a strategic plan to improve the health status of the population through the promotion of a healthy lifestyle, prevention of illness, and improvement of service delivery.

The National Department of Health $(2013,32)$ states that breastfeeding should be initiated early post-delivery. When medical conditions present and the mother and infant are separated post-delivery, a breastmilk substitute may be given to the infant for a day or two while the mother recovers in the post-natal unit. The South African Nursing Council (1984) emphasises that a registered midwife has the responsibility to provide scientific procedures related to the care of the mother and the infant during pregnancy, labour, and puerperium. The researchers observed that patients who had an emergency or elective caesarean needed improved quality and sensitive care before and after the operation, and assistance to adjust to the reality of post-operative effects. The findings of this study will guide the nursing and midwifery profession on the way in which to improve the quality of care provided to patients before and after a caesarean section. 


\section{Purpose and Objective of the Study}

The purpose of the study was to explore and describe patients' lived experiences of the care provided before and after a caesarean section in the City of Tshwane, Gauteng.

\section{Methods}

A qualitative, exploratory and descriptive design was adopted to explore and describe the lived experiences of women of the care provided before and after a caesarean section in the City of Tshwane, Gauteng. The women had had caesarean sections at different hospital levels (district, regional, and tertiary hospitals) in the City of Tshwane, and had been discharged to attend local clinics for follow-up visits. Data collection was done at the local clinics where postnatal care is provided to women who attended the follow-up care programme. Purposive sampling was used, and the inclusion criteria were participants who had a caesarean section in the current perinatal period, were 18 years old and older, willing to participate, and able to communicate in English, Setswana, Sepedi, or Northern Sotho. The sample size was 11 participants, as determined by data saturation.

The data collection method was individual in-depth interviews using an interview schedule that consisted of two sections. Section A gathered specific biographical information that described the population, which included age, gravidity, parity, number of caesarean sections, and indications for the caesarean section. This information was used to contextualise the findings. Section B consisted of one central question: "Please tell me how you experienced the care given to you before and after the caesarean section during the current perinatal period." The central question was followed by probes, paraphrasing, and reflections. Three interviews were conducted as a pilot study to test the skills of the interviewer, the interview schedule, the time required to conduct the interviews, the suitability of the environment, and the chosen data analysis approach. After pretesting, problems were identified, and the interview schedule was modified to improve the quality of data collection.

\section{Trustworthiness}

Trustworthiness is projected to maintain validity and reliability in a qualitative study. The primary principles of trustworthiness are credibility, transferability, dependability and confirmability (Table 1) (Botma et al. 2010, 292). 
Table 1: Strategies to enhance trustworthiness in qualitative data

\begin{tabular}{|l|l|l|}
\hline Trustworthiness & Criteria & Application \\
\hline Credibility & $\begin{array}{l}\text { Building } \\
\text { rapport with } \\
\text { the participants }\end{array}$ & $\begin{array}{l}\text { The principal researcher built a trusting } \\
\text { and pleasant relationship to gain } \\
\text { confidence and trust. The interviews } \\
\text { were conducted in private rooms. }\end{array}$ \\
\cline { 2 - 3 } & Flexibility & $\begin{array}{l}\text { The sample size was determined by } \\
\text { data saturation. }\end{array}$ \\
\cline { 2 - 3 } & $\begin{array}{l}\text { Dominion of } \\
\text { the researcher }\end{array}$ & $\begin{array}{l}\text { The researcher had a BTech in nursing } \\
\text { science, a postgraduate diploma in } \\
\text { public health, and four years } \\
\text { experience in a maternity unit. }\end{array}$ \\
\cline { 2 - 4 } & Peer review & $\begin{array}{l}\text { The Faculty Research and Innovative } \\
\text { Committee approved the study. } \\
\text { The Ethics Committee of Tshwane } \\
\text { University of Technology analysed the } \\
\text { study. } \\
\text { A colloquium before peers allowed } \\
\text { peers to evaluate the study. }\end{array}$ \\
\hline Transferability & Stability & $\begin{array}{l}\text { The interview schedule was piloted } \\
\text { before starting with data collection. } \\
\text { Data gathering arrangements were } \\
\text { made for participants to be interviewed } \\
\text { until data saturation was achieved. The } \\
\text { research results can be transferred to } \\
\text { similar situations. }\end{array}$ \\
\hline Confirmability & $\begin{array}{l}\text { Independent } \\
\text { coder }\end{array}$ & $\begin{array}{l}\text { The interpretations of the findings are } \\
\text { supported by the data collected. }\end{array}$ \\
An experienced co-coder was used. \\
\hline Dependability & Inquiry audit & \\
& &
\end{tabular}

\section{Ethical Considerations}

The application letters and the research proposal were submitted to the Tshwane University of Technology, and the Tshwane Research committee for their approval. Ethical clearance was obtained from the Faculty Committee for Ethics of the Tshwane University of Technology (FCRE 2018/09/06(02) (SCI), and the Tshwane Research Committee granted a clearance certificate (Letter reference: GP 201902039). Permission to conduct the study at the local clinics was granted by the managers of the Tshwane District Clinics at Phedisong 4, Skinner and Danville. The information obtained from the participants was kept confidential, and no information was used to exploit a particular institution. The names of the participants were not included in the 
data collection tools. The information leaflets were translated into the participants' languages. The participants were recruited for voluntary participation in the study. They were informed in advance that the interviews would be audio recorded. The participants' autonomy was respected. Before participating, the women were given information about the study in a private room, and their role of participation was explained. Those who agreed to participate were given consent forms to sign to confirm their willingness to participate in the study.

\section{Analysis}

Data analysis started after the first interview was completed. All audio-taped data were listened to and trancribed verbatim (Botma et al. 2010, 214). The data analysis followed Tesch's eight-step approach of content analysis (Creswell and Creswell 2017, 311). This approach includes making sense of the data, analysing the transcriptions, listing the topics, assembling the data, and re-coding the existing data.

\section{Findings of the Study}

The participants were identified by using letters of the alphabet to protect their identities and to give significance to their responses. This section provides the findings and discusses the themes and subthemes generated from the transcriptions. The themes were elective and emergency caesarean sections, reflections on peri-operative care, reflections on post-operative care, and improving quality of care. The themes and subthemes are outlined in Table 2.

Table 2: Themes and subthemes

\begin{tabular}{|l|l|}
\hline Theme & Subthemes \\
\hline Elective and emergency caesarean & Indications related to the mother \\
\cline { 2 - 2 } section & Indications related to the foetus \\
\hline Reflections on peri-operative care & $\begin{array}{l}\text { Mixed emotions and pain } \\
\text { Poor nursing care and support }\end{array}$ \\
\hline Reflections on post-operative care & Negative and positive reflections \\
\cline { 2 - 2 } & Breastfeeding reflections \\
\hline Improving quality of care & $\begin{array}{l}\text { Information provided to the mothers } \\
\text { Support and monitoring }\end{array}$ \\
\hline
\end{tabular}

\section{Theme 1: Elective and Emergency Caesarean Sections}

The results indicated that all 11 participants were informed about the indications for a caesarean section. The findings from the study revealed subthemes of the emergency and elective caesarean sections. The participants who had an emergency caesarean section expressed their disappointment and the feeling of being unprepared for this 
major procedure. However, they emphasised that, amid the unpleasant emotions, they gained courage by the thought of having a baby that is alive. The participants who had a planned caesarean section believed that it was impossible to have a normal vaginal delivery owing to a previous caesarean section or breech presentation. Some of the narratives are as follows:

They were inducing me so it failed. They were giving me medication to drink but, it failed. (Participant J (22 years, G1 P1))

I was actually going to deliver naturally, my time was overdue, I was in labour for a long time so, I had emergency caesar. I was transferred to another hospital, immediately when I arrived there. I signed the form for C-section. (Participant A (25 years, G1 P1))

It was my second caesar ... they told me it's possible to have the baby normal delivery they gave me a date for caesar delivery. (Participant B (33 years, G2 P2))

The baby was tired; they said my baby was stressing. I was not ready especially that I didn't have any complications during pregnancy. They were saying if they take too much time I could lose the baby. (Participant G (27 years, G1 P1))

The buttocks were coming out first. My baby was not in a normal position. At that time, I just wanted everything to be done. Then I signed the consent. (Participant C ( 27 years, G1 P1))

\section{Theme 2: Reflections on Peri-Operative Care}

The participants expressed that being in theatre was not a pleasant experience because the outcomes were unpredictable owing to the nature of the operation. However, once the baby was born, the participants experienced relief, joy, and happiness to see the baby alive. The participants explained that the midwives and doctors were supportive and comforting in theatre. The participants whose babies were transferred urgently to the neonatal intensive care unit (NICU) expressed the feeling of being relieved to see the baby alive, but worried about the sudden transfer without bonding with the baby immediately after birth. The subthemes were experiences of mixed emotions, pain and miscommunication. The findings in the current study showed that some patients did not expect to be told to be active and walk around to prevent complications arising from continued bedrest. They expressed their views as follows:

It was scary in theatre. I just wanted the baby to come and be over it actually, they showed me my baby and then they did the skin on skin on my chest. So, when the nurses showed me my baby, I couldn't believe it. (Participant F (24 years, G1 P1))

After my baby was born, I just heard the doctor telling the nurse to take the baby to the ICU and then I got worried. The baby was taken from there at that time and I saw my baby after five o'clock in the afternoon. I was worried about my baby's conditions. (Participant E (40 years, G2 P2)) 
When the baby was delivered, they showed me the bottom part of my baby, they showed me the gender and then they took my baby. I didn't do the skin-to-skin with the baby. I was happy that I finally delivered after such a long time. (Participant J (22 years, G1 P1))

I asked that can I please hold the baby. The nurse, didn't give me the baby. She was like no, we will bring the baby inside the ward and everything. So I said to myself, okay it is not a private hospital. If I paid them, they were going to do it. I didn't have a problem with anyone; I was fine, I was happy that I had my baby. (Participant C (27 years, G1 P1))

My baby was admitted in another ward, so they discharged me and told me to go where the baby. I was not asking for any medication nurse were giving me pain medication. The only thing they assisted me with every day is that a nurse took me where my baby was after two days, it was only after the sister in charge who was there spoke to the sisters and in fact, she was upset on why they didn't take me to the baby. (Participant D (43 years, G3 P3))

I was given medications and assessed my body to check if am fine. I believe they didn't tell more information thinking I know since it is not my first baby. No information was provided post-delivery on what will happen. Just because we don't ask them anything it doesn't mean we are fine. Sometimes, because of the attitude we get, we are afraid to ask for help. (Participant K (29 years, G2 P1 previous termination of pregnancy))

\section{Theme 3: Reflections on Post-Operative Care}

The subthemes that emerged from post-operative care were positive and negative reflections. The participants who had an emergency caesarean section mentioned that the post-delivery care and routine were unexpected. Mobility was restricted for six to eight hours, and they were not allowed to eat or drink fluids after delivery. All participants reported that they were expected to have bedrest and to mobilise after six to eight hours in the postnatal unit. The participants mentioned that they received warm blankets and that the room was warm for the baby. They furthermore explained that they did not expect to feel intensive pain after delivery. Although pain medications were administered regularly, the pain was persistent.

Most of the participants mentioned that breastfeeding was done in a lateral position on the bed before mobility was initiated. They added that it was difficult to attach the baby to their breast, as sometimes the baby would be restless. Difficulties in breastfeeding were related to poor attachment, position restriction and pain. Rooming was practiced as the mothers were sleeping with or next to the baby. Some participants mentioned that nurses and midwives would come and help with the baby, but it was not done regularly. However, a demonstration of attachment of the baby to the breast was done. Most of the participants stated that it was difficult to adjust to a supine position and emphasised that nurses and midwives should help with infant-feeding and nappy changing. A few participants formula-fed their babies owing to poor lactation. 
The participants whose babies were admitted to the NICU expressed the frustration of not being updated about the condition of the baby, which led to more concerns and worries. The participants who had an elective caesarean explained that their treatment had not improved. If the treatment were similar to previous post-delivery care, or if it were possible to have a normal vaginal delivery, the situation could have been different. The following are some of the reflections by the participants:

No information was provided post-delivery on what will happen. Just because we don't ask them anything it doesn't mean we are fine. Sometimes, because of the attitude we get, we are afraid to ask for help. (Participant K (29 years, G2 P1 previous termination of pregnancy))

It was painful; I was supposed to stand up after six to eight hours too. It was harder first but now it is normal, I had to do it, they told me to clean the cord with the surgical spirit. (Participant H (21 years, G1 P1))

I felt neglected by the staff because, they didn't care about my feelings and I just ... it's caesar its major and I have to be taken care of. They have to ask if I need assistance then, I can respond to that. I feel like you can't complain whatever you feel there you just keep quiet, you just push time so that you can leave. (Participant F (24 years, G1 P1))

The following morning a nurse took me to neonatal ward to breastfeed my baby. They asked me to try and stand up and walk around the nurse was with me. They taught me how to attach the baby on the breast then I continued. The nurses assisted me to care for the baby and dress the baby. It was painful after giving birth, they were giving me injections and pills for the pain. They showed me how to clean the cord. (Participant A (25 years, G1 P1))

The nursing students showed me how to attach the baby on the breast the nurses, said I can sleep for an hour before walking and then I slept for 1 hour and 30 minutes and I stood up afterwards. I was given a drip stand to balance my body to mobilise. They said I should pour surgical spirit on a cotton and clean the cord. (Participant I (24 years, G1 P1))

The nurses taught me how to breastfeed... I was on bedrest on the day after the operation and the following day the nurses said I can start walking around. It was my responsibility as the mother and I had to look after my baby. (Participant E (40 years, G2 P2))

The nurse came and said feed the baby, they would attach him on the breast and he would suck. It was difficult because it was the first time but she helped me. They brought a chair and said I have to sit on it, the nurse assisted me to get off the bed and sit on the chair. So, I had to walk, it was not easy. They don't assist you. They want you to do it yourself. (Participant C (27 years, G1 P1)) 


\section{Theme 4: Improving Quality of Care}

According to the results, the subtheme that emerged was support. Women emphasised that there was insufficient provision of information. All participants knew the indications for their caesarean sections; however, they did not understand what the diagnoses meant. The study results indicated that, post-delivery, patients were not informed about possible complications related to the caesarean section. The participants expressed that some nurses and midwives were professional and helpful, but that a few had a negative attitude and made it difficult for them to ask for assistance. The participants suggested an improvement in promoting comfort, independence, management of pain, initiation of mobility, infant feeding, and cord care. Some of the narratives are as follows:

I think they need to explain everything in full because, sometimes I wonder, why couldn't I have normal delivery. They know more than me so, you just do whatever they say, so I think they can explain nicely for us to understand, what they are doing. (Participant D (43 years, G3 P3))

Maybe they could just offer mothers with depression counselling ... I would preferred them to ask me if I am ok and how do you feel everyday, they should just be really nice to patients and be thoughtful. (Participant H (21 years, G1 P1))

They should constantly check the patients, while we are sleeping. There should be someone who monitors the mothers with their babies and check if they are not sick or to ask if patients needs something. (Participant I (24 years, G1 P1))

\section{Discussion}

\section{Theme 1: Elective and Emergency Caesarean Sections}

Bhandar $(2017,286)$, in a study conducted in Nepal, showed that common indications for a caesarean section were foetal distress, obstructed labour, failed induction, prolonged second stage of labour, antepartum haemorrhage, previous caesarean section, multiple pregnancies, malpresentations, and medical-related conditions. There are similarities of this study and the current study. The study conducted in Nigeria by Panti et al. $(2018,25)$ showed that a caesarean section performed as an obstetric emergency intervention may prevent foetal and maternal morbidity and mortality. The study further agreed that previous experiences and cultural factors may influence an individual's perception about a caesarean section. Furthermore, Anikwe et al. $(2019,2668)$, in a study conducted in South East Nigeria, found that respondents who had an emergency caesarean section were disappointed by the reality that a normal vaginal delivery attempt had failed and that the last resort was a caesarean section to save the baby. 


\section{Theme 2: Peri-Operative Care}

In a study conducted by Lanning et al. $(2019,112)$ in the United States of America (USA), the findings indicated a need to support the initiation of skin-to-skin after caesarean sections in theatre as even though nurses and midwives were committed to initiate skin-to-skin in the operating room, staff shortages and workloads were identified as challenges to maintaining the practice. However, in the current study, the nurses and midwives did the skin-to-skin practice in the ward, although a few women were given the opportunity to perform the practice in theatre.

Armbrust et al. (2016, 163) conducted a study in Germany which showed that indeed it was a routine practice during a caesarean section that, after a surgeon cut the umbilical cord, the baby was handed over to the midwife and examined before being shown to the mother. After vaginal delivery, however, the baby was given directly to the mother to promote early skin-to-skin contact. Early promotion of interaction between the mother and child has a progressive impact, as it promotes mother-baby bonding and breastfeeding. In the current study findings, the mother and new born bonding was done minimally. In the cases of some women, the promotion of bonding was done early postdelivery, whereas for a few others it took more than an hour for the mother to see the baby owing to theatre procedures, which worsened the delay in bonding.

A descriptive cross-sectional study conducted in Pakistan by Vusqa, Liaqat, and Safdar $(2019,1521)$ revealed that the majority of women who had a caesarean section under regional anaesthesia reported that positive conversations among the multidisciplinary team in theatre were very helpful to ease their anxiety and fears. Moreover, the awareness of the surroundings during the operation had a positive influence on the psychological and emotional well-being of the patients. The current study findings agree and show that the women regarded the conversations with the multidisciplinary team as helpful and that they reduced levels of frustration.

\section{Theme 3: Post-Operative Care}

The participants were able to share post-operative care experiences. A helping-trusting human care relationship is essential to transpersonal caring and the expression of both positive and negative feelings in the nurse-patient relationship (Alharbi and Baker 2020, 6).

In a study conducted in Ireland by Nagal and Farrely $(2018,84)$, it was found that nurses would focus more on physical well-being and were less concerned about the emotional well-being of the patients. Owing to the increased workload of the nursing staff, the women hesitated to ask for the assistance they needed. Nurses should recognise patients' basic needs during the pre-, peri-, and post-operative period, and offer support and information. Nurses should recognise that internal and external environments influence the health and illness of a patient. The above study had similar findings to the current 
study findings that most participants felt the information provided was insufficient, and that there was a lack of emotional support from the nurses and midwives.

Badr et al. $(2018,22)$ conducted a study in the USA which emphasised that 79 per cent of mothers who experienced depression two to three days post-partum were mothers with babies transferred to the NICU. However, various other factors contributed to postpartum depression such as complications during pregnancy, labour, lack of social support, and history of depression. Pain is one of the symptoms that women experienced as unpleasant and challenging and needs to be managed sufficiently. The findings complement current study findings as women who were separated from their babies were anxious, worried and frustrated by not knowing about the condition of their babies. Simultaneously, the women experienced absence of emotional support from the nurses and midwives which made it difficult for them to adjust to post-operative effects and which in turn made the healing process challenging.

A cohort comprehensive study conducted by Ples et al. $(2018,72)$ in Romania supported that 30.9 per cent of patients who had a caesarean section mentioned that the pain intensity decreased from the third day post-delivery. The current study had similar findings in which the majority of women mentioned poor pain management, and elaborated that even though they were informed that they have been given pain medications, the pain was persistent.

A qualitative study was conducted to investigate stress management in NICUs in Iran (Heidari, Hasanpour, and Fooladi 2017, 29) which also agrees with the current study that disrupting parent-infant bonding created anxiety, emotional detachment, and stress for the parents. Moreover, the lack of information regarding the condition of the baby may lead to anxiety and frustration for the partner and the family. Mothers with babies admitted to the NICU also need sympathy and assistance, including updates on treatment from the medical staff.

\section{Theme 4: Improving Quality of Care}

The study results showed that most of the participants felt that they were not adequately supported emotionally stating that the nurses were more concerned about caring for the operation site. The participants also felt that the information provided was insufficient. They elaborated that nurses should be available when needed by patients as all patients have unique needs. The study by Bernstein and Teigen $(2017,6)$ in the USA has similar suggestions to the current study findings about the importance of psychological preparation. This study findings emphasised that patients needed to be educated and well informed before the caesarean section. Education and information can be initiated at an appropriate literacy level during antenatal visits. Bernstein and Teigen (2017) further elaborate that, in some circumstances of an emergency caesarean section, information or education omitted can still be explained to the patient in theatre, during postnatal care, or upon discharge. 
Srivastava et al. $(2015,10)$ conducted a study in India which complements the current study findings found that maternal satisfaction in the hospital is influenced by various factors including good building infrastructure with water supply, electricity, beds, cleanliness, adequate room space, seating arrangements, and the availability of doctors, midwives, and nurses at all times. A descriptive cross-sectional study by Stellenberg and Abrahams $(2015,4)$ in South Africa further elaborates that maternal satisfaction care can be improved through therapeutic communication, which included listening skills, politeness, prompt pain relief, kindness, approachability, smiling, and good caring behaviour. Anikwe et al. $(2019,2664)$ emphasised that nurses should have an active engagement whereby information about matters such as infant feeding, pain management, early mobility, and oral intake is well communicated.

\section{Limitations of the Study}

The data collection took longer than anticipated, as babies were prioritised during the data collection. The data collection method was self-report, which could lead to recall bias. The data gathering probing did not include experiences of the patients of the care provided by the doctors and other multidisciplinary team members, before and after the caesarean section birth.

\section{Recommendations}

\section{Nursing Practice}

Good communication is the way to identify the needs of patients. Therefore, health education should be provided throughout the antenatal, labour, and postnatal period until discharge. Health professionals and family need to provide continuous emotional and psychosocial support. Counselling services should be offered by trained professionals to help with various challenging situations. Support groups should be encouraged to empower and help women to deal with or overcome experienced challenges.

\section{Nursing Education}

The nursing education curriculum should focus on improving health education, communication, and teaching skills on caring for patients before and after a caesarean section. There should be regular in-service training programmes to educate nursing students, nurses, and midwives to develop effective communication, health, and teaching skills to deal with patients and families.

\section{Nursing Research}

There is a need for more studies on a greater scale in various parts of South Africa so comparisons can be made between representative results. Further studies need to be conducted on the care provided by the other multidisciplinary team members to 
complete a plan for improved quality care. More studies need to be conducted on the prevalence and management of pain after a caesarean section. Research should be conducted to design a nursing and midwifery framework on caring for women before and after a caesarean section.

\section{Conclusion}

The study described and explored patients' lived experiences of care before and after a caesarean section. The factors influencing the quality of care were related to the insufficient provision of information or health education related to the health condition of the mother and the infant. The participants reported poor support and lack of assistance from nurses and midwives, and persistent pain even after the administration of pain medications. Moreover, the study revealed the importance of quality care that involves good communication with patients, listening attentively to patients, and involving the family in decision-making. Effective communication is the key to identifying women's expectations regarding care.

\section{Acknowledgements}

The authors thank the Adelaide School of Nursing Science, the Tshwane University of Technology, the clinic managers, the field worker, and the study participants.

\section{References}

Alharbi, K. N., and O. G. Baker. 2020. “Jean Watson's Middle Range Theory of Human Caring: A Critique." International Journal of Advanced Multi-Disciplinary Scientific Research 3 (1): 1-13. https://doi.org/10.31426/ijamsr.2020.3.1.3011.

Anikwe, C. A., E. C. Egbuji, N. E. Brown, C. C. Ikeoha, J. O. Egede, and S. T. Adeoye. 2019. "The Experience of Women following Caesarean Section in Tertiary Hospital in South East Nigeria." African Health Sciences 19 (3): 2660-8. https://doi.org/10.4314/ahs.v19i3.42.

Armbrust, R., L. Hinkson, K. von Weizsacker, and W. Henrich. 2016. "The Charité Caesarean Birth: A Family Orientated Approach of Caesarean Section." Journal of Maternal-Fetal and Neonatal Medicine 29 (1): 163-8. https://doi.org/10.3109/14767058.2014.991917.

Badr, K. L., N. Ayvazian, S. Lameh, and L. Charafeddine. 2018. "Is the Effect of Postpartum Depression on Mother-Infant Bonding Universal." Infant Behavior and Development 51: 15-23. https://doi.org/10.1016/j.infbeh.2018.02.003.

Bernstein, P. S., and M. D. K. Teigen. 2017. "A Program of Enhanced Recovery after Cesarean Birth to Improve Post-Operative Recovery and Reduce Hospital Length." Journal of Albert Einstein College of Medicine of Yeshiva University Feb: 1-9. 
Bhandar, B. R. 2017. "Indications and Foetal Outcomes of Caesarean Section in Sindhu Sadabahar Hospital, Sindhupalchok." Kathmandu University Medical Journal 15 (60): 284-7.

Botma, Y., M. Greef, F. M. Mulaudzi, and S. C. D. Wright. 2010. Research in Health Science. Cape Town: Heinemann.

Creswell, J. W., and J. D. Creswell. 2017. Research Design: Qualitative, Quantitative and Mixed Methods Approaches. 5th ed. Thousand Oaks: Sage.

Guidelines for Maternity Care in South Africa. 2015. "A Manual for Clinics, Community Health Centres and District Hospitals.” Accessed 9 March 2018. https://healthe.org.za/2015/11/17/guidelines-maternity-care-in-south-africa/.

Heidari, H., M. Hasanpour, and M. Fooladi. 2017. "Stress Management amongst Parents of Neonates Hospitalised in NICU: A Qualitative Study." Caring Sciences Journal 6 (1): 2938. https://doi.org/10.15171/jcs.2017.004.

Hoxha, L., L. Syrogiannouli, M. Braha, D. C. Goodman, B. C. Costa, and P. Jüni. 2017. "Caesarean Sections and Private Insurance: Systematic Review and Meta-Analysis." BMJ Open 7 (8): e016600. https://doi.org/10.1136/bmjopen-2017-016600.

Koffi, A., A. D. Kouamé, C. Kakou, A. C. Roland, F. A. Diomande, A. Kimou, and N. K. L. Pacome. 2017. "How Referred Patients Influence Cesarean Sections Rate Pattern: Analysis according to the Robson Classification." Open Journal of Obstetrics and Gynecology 7 (11): 1132-40. https://doi.org/10.4236/ojog.2017.711114.

Lanning, R. K., M. H. Oerman, J. Waldrop, L. G. Brown, and J. A. Thompson. 2019. “Doulas in the Operating Room: An Innovative Approach to Supporting Skin to Skin Care During Caesarean Birth.” Journal of Midwifery and Women's Health 64 (1): 112-7. https://doi.org/10.1111/jmwh.12930.

Nagal, U., and M. Farrely. 2018. "Women's Views and Experiences of having their Mental Health Needs Considered in the Perinatal Period." Midwifery 66: 79-87. https://doi.org/10.1016/j.midw.2018.07.015.

National Department of Health. 2013. "Infant and Young Child Feeding Policy." Accessed 25 October 2019. https://www.health-e.org.za/2013/09/20/infant-young-child-feed-policy$2013 /$.

National Department of Health. 2014. "Strategic Plan Department of Health 2014/15 to 2018/19." Accessed 24 March 2018. http://www.gov.za/departmentofhealthstrategicplan2014/15-2018/19.pdf.

Panti, A. A., A. M. Nasir, A. D. Saidu, J. A. Garba, K. A. Tunau, and R. Ibrahim. 2018. "Perception and Acceptability of Pregnant Women towards Caesarean Section in Nigeria." European Journal of Pharmaceutical and Medical Research 5 (3): 24-9. 
Ples, L., R. M. Sima, C. Delia, A. Camelia, O. Denisa, A. Balalau, D. Anca, and G. O. Ocatavian. 2018. "The Psychosocial Impact of Vaginal Delivery and Cesarean Section in Primiparous Women.” Journal of Mind and Medical Sciences 5 (1): 70-4. https://doi.org/10.22543/7674.51.P7074.

South African Nursing Council. 1984. "Regulation Relating to the Scope of Practice of Persons who are Registered or Enrolled under the Nursing Act, 1978." Accessed 29 February 2020. https://sanc.co.za/regulat/Reg-scp.htm.

Srivastava, A., B. Avan, P. Rajbangshi, and S. Bhattacharyya. 2015. "Determinants of Women's Satisfaction with Maternal Health Care: Review of Literature from Developing Countries." BMC Pregnancy and Childbirth 15: 97. https://doi.org/10.1186/s12884-0150525-0.

Stellenberg, E., and J. M. Abrahams. 2015. "The Prevalence of and Factors Influencing PostNatal Depression in a Rural Community in South Africa." African Journal of Primary Health Care and Family Medicine 7 (1): 874. https://doi.org/10.4102/phcfm.v7i1.874.

Vusqa, U. T., H. Liaqat, and S. S. Safdar. 2019. "The Influence of Operation Theatre Environment on Patients' Perceptions During Awake Procedures: A Cross-Sectional Study." Journal of the Pakistan Medical Association 69 (10): 1521-5. https://doi.org/10.5455/JPMA.299192.

WHO (World Health Organization). 2015. "Caesarean Sections should only be Performed when Medically Necessary.” Accessed 25 February 2018. www.who.int/Mediacentre/News/Releases/2015/Caesarean-Sections/En/.

WHO (World Health Organization). 2016. "What is Quality of Care and Why is it Important?" Accessed 10 March 2018. https://www.who.int/maternal_child_adolescent/topics/qualityof-care/definition/en/. 